\title{
Bactérias indígenas e morfopedologia de um Latossolo Vermelho Amarelo no cerrado piauiense
}

\section{Stéfany Thainy Rocha Porto ${ }^{1}, *$, Bruna de Freitas Iwata ${ }^{2}$, Laécio Miranda Cunha ${ }^{1}$, Suiany Spanic Rocha Porto ${ }^{1}$ e Israel Lobato Rocha $^{1}$}

${ }^{1}$ Instituto Federal do Piauí - IFPI. Campus Corrente. Corrente-PI, Brasil (CEP 64980-000).*E-mail: stefanytrp@gmail.com.

${ }^{2}$ Instituto Federal do Piauí - IFPI. Campus Teresina Central. Praça da Liberdade, S/No. Centro. Teresina-PI, Brasil (CEP 64000-040).

Resumo. Considerando a importância de reconhecer os aspectos morfológicos e de formação dos solos, assim como suas características biológicas, este estudo teve como objetivo caracterizar a formação das comunidades bacterianas e a pedologia de um Latossolo Vermelho Amarelo no Cerrado Piauiense. Para o desenvolvimento do mesmo utilizaram-se as metodologias listadas nos manuais de descrição e coleta de solo no campo e o Sistema Brasileiro de Classificação do solo para a descrição morfológica da área de estudo e do perfil de solo estudado. A caracterização das comunidades indígenas bacterianas deu-se através da coleta de solo nas profundidades de $0-20 \mathrm{~cm}, 20-40 \mathrm{~cm}, 40-60 \mathrm{~cm}, 60-80 \mathrm{~cm}, 80-100 \mathrm{~cm}$, no qual foram triadas e encaminhadas para análise. Com as análises físicas, químicas e o estudo da geologia do local o solo estudado é classificado como um Latossolo Vermelho Amarelo Distróficos Típicos. Esses solos são caracterizados por serem bastante profundos e quimicamente pobres. Em relação à descrição do perfil o mesmo apresenta horizonte A e B, como também uma transição entre os dois horizontes. As comunidades indígenas bacterianas apresentam uma grande quantidade de bactérias com uma ótima capacidade de adaptação às alterações do meio.

Palavras-chave: Microbiologia do solo; Morfologia; Classificação de solo.

Abstract. Indigenous bacteria and morphogology of a Yellow
Red Latosol in the Cerrado Piauiense. The importance of
obtaining the morphological and soil formation aspects as well as
their biological presentation, this study aimed to characterize a
community of bacteria and a pedology of a Yellow Red Latosol in
the Cerrado of Piauiense. For the development of the same the
methodologies listed in the manuals of description and soil
collection in the field and the Brazilian System of Classification of
the soil for the morphological description of the study area and
the studied soil profile were used. The characterization of the
indigenous bacterial communities occurred through the
Recebido:

26/03/2019

Aceito:

$21 / 04 / 2019$

Publicado:

$30 / 04 / 2019$

Acesso aberto

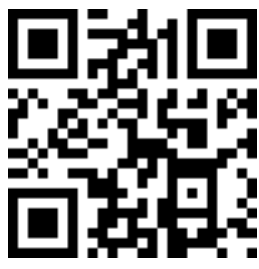

ORCID

(1) 0000-0002-2606-9204 Stéfany Thainy Rocha Porto

(D) 0000-0002-6465-9731 Bruna de Freitas Iwata

D 0000-0002-8147-8019 Laécio Miranda Cunha D) 0000-0003-3430-6043 Suiany Spanic Rocha Porto

(D) 0000-0002-4496-9935 Israel Lobato Rocha 
collection of soil at depths of $0-20 \mathrm{~cm}, 20-40 \mathrm{~cm}, 40-60 \mathrm{~cm}, 60-80$ $\mathrm{cm}, 80-100 \mathrm{~cm}$, in which they were sorted and sent for analysis. With the physical-chemical analysis and study of the geology of the site the studied soil is classified as a Typical Red Yellow Latossolo Dystrophic. These soils are characterized by being very deep and chemically poor. In relation to the description of the profile it presents horizon $\mathrm{A}$ and $\mathrm{B}$, as well as a transition between the two horizons. Bacterial indigenous communities present a large amount of bacteria with an excellent ability to adapt to changes in the environment.

Keywords: Soil microbiology; Morphology; Soil classification.

\section{Introdução}

Ocupando maior parte do manto da superfície do planeta, o solo é um agrupamento de corpos naturais constituídos por partes sólidas, liquidas e gasosas, é um corpo tridimensional e dinâmico, formado por materiais minerais e orgânicos contendo matéria viva que podem ser vegetadas na natureza ou eventualmente terem sido modificados pela a ação humana (Santos, 2013). Esse recurso atua como mediador entre a hidrosfera, litosfera, biosfera e atmosfera, influenciando na qualidade da água e do ar, como também fornecendo nutrientes para as plantas (Lepsch, 2011).

A sua formação se dá através da degradação das rochas, ocasionadas pelo intemperismos físicos, químicos $\mathrm{e}$ agentes biológicos, tendo como principais fatores de formação o material de origem, relevo, clima, tempo e os organismos, esses elementos contribuem para o complexo comportamento morfológico dos solos. Logo a morfologia do solo trata sobre a descrição de propriedades observadas pela visão e tato, podendo analisar a cor, textura, estrutura, porosidade, consistência e transição entre os horizontes (Santos, 2015).

O solo é um habitat natural em constate transformação, possui características peculiares em relação aos outros habitats terrestres, é constituído por comunidades biológicas, nas quais se encontram em diferentes formas de microrganismos (Siqueira et al., 2006). Os microrganismos do solo são influenciados pelo o ambiente, diante disto, qualquer modificação poderá influenciar as comunidades microbianas deste recurso (Mesquita, 2011).

Muitas das propriedades do solo são desinentes das ações dos microrganismos (Hungria e Araújo, 1994). As principais atividades exercidas pelos os organismos são a decomposição da matéria orgânica, produção de húmus, ciclagem de nutrientes e energia (incluído a fixação de nitrogênio na atmosfera), produção de compostos complexos que contribuem para a agregação no solo, decomposição de xenobióticos e controle biológico de pragas e doenças (Moreira e Siqueira, 2006).

Considerando a importância de reconhecer os aspectos morfológicos e de formação dos solos, assim como suas características biológicas, este estudo teve como objetivo caracterizar a formação das comunidades bacterianas e a pedologia de um Latossolo Vermelho Amarelo no Cerrado Piauiense.

\section{Material e métodos}

estudo

Caracterização da área de

0 estudo foi realizado na área do Instituto Federal do Piauí, localizado no Município de Corrente, na região do extremo sul do Estado do Piauí (Figura 1), com uma latitude de $10^{\circ} 26^{\prime} 36^{\prime \prime}$ sul e longitude $45^{\circ} 09^{\prime} 44^{\prime \prime}$ oeste. 
Segundo o IBGE (2010), o Município de Correntes possui uma população estimada para o ano de 2017 de 26.205 habitantes e abrange uma área de aproximadamente $3.048 .447 \mathrm{~km}^{2}$, possui clima tropical subúmido quente e está situado na área do Bioma Cerrado (CEPRO, 2017).

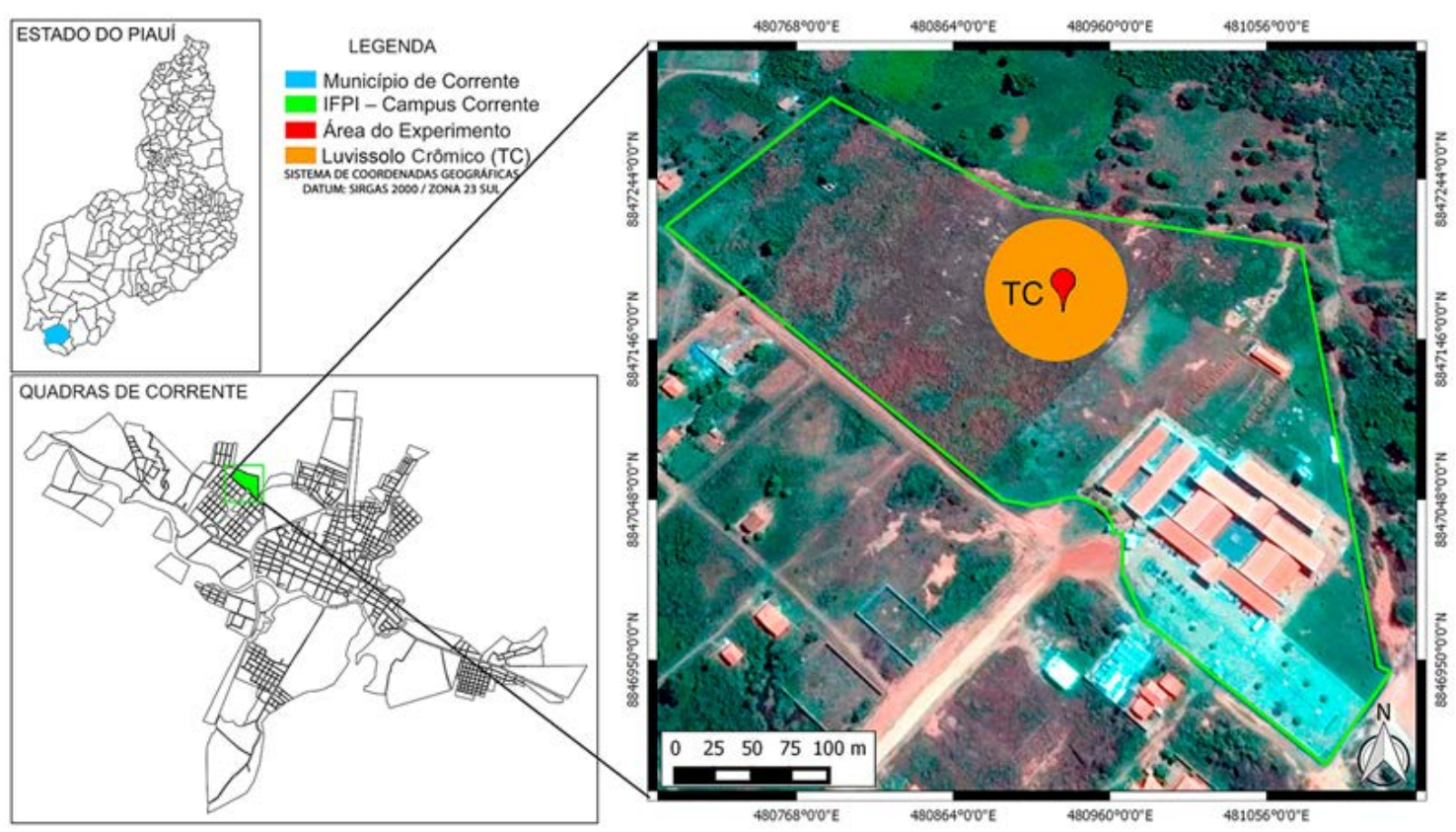

Figura 1. Mapa de localização da área de estudo.

\section{de estudo}

Descrição morfológica da área

Para a descrição morfológica da área utilizou-se as metodologias listadas nos Manuais de descrição e coleta de solo no campo e o Sistema Brasileiro de Classificação do solo (Santos, 2013; Santos, 2015).

\section{do solo \\ Descrição morfológica do perfil \\ A descrição morfológica do solo} foi realizada por meio da abertura de uma trincheira, com proporções de $1,50 \mathrm{~m} \times 1,80 \mathrm{~m}$ e a área de acesso, utilizando-se a metodologia de Santos (2015). Após abertura da trincheira, executada através de ferramentas manuais, como enxadeco, chibanca e pá, foram analisados os atributos descritos na Tabela 1.

\section{Relação solo-paisagem}

Para avaliação do perfil de solo, foram levantados os componentes ambientais da área em estudo, considerando a localização, situação de declive, cobertura vegetal, geologia geomorfologia e grau de conservação do ambiente.

\section{Caracterização das comuni- dades bacterianas indígenas do solo estudado}

Foram coletadas amostras de solo na profundidade de $0-20 \mathrm{~cm}, 20-40 \mathrm{~cm}$, $40-60 \mathrm{~cm}, 60-80 \mathrm{~cm}, 80-100 \mathrm{~cm}$. As amostras foram triadas e encaminhadas para caracterização dos grupos presentes no laboratório de microbiologia em parceria com o Instituto Federal do Piauí, Campus Teresina Central (Figura 3). 
Tabela 1. Análises morfológicas do perfil de solo estudado.

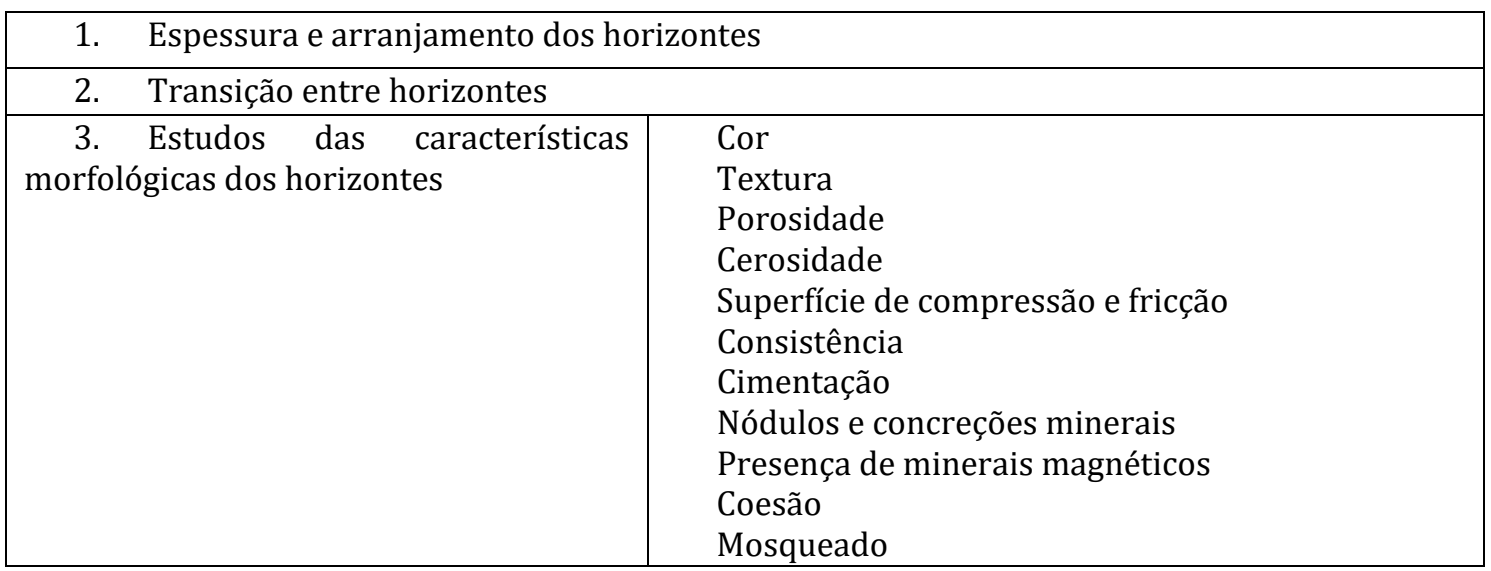

Fonte: Adaptado de Santos (2015).

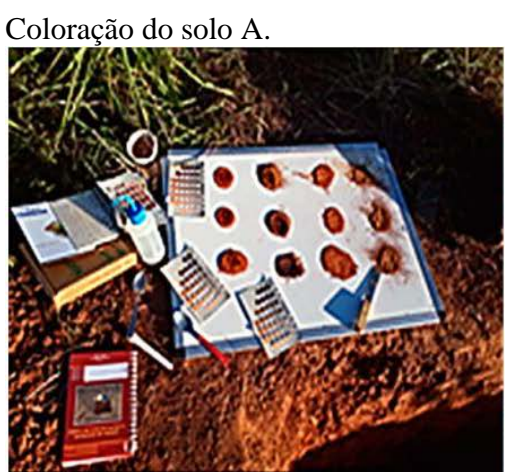

Consistência do solo molhado D.

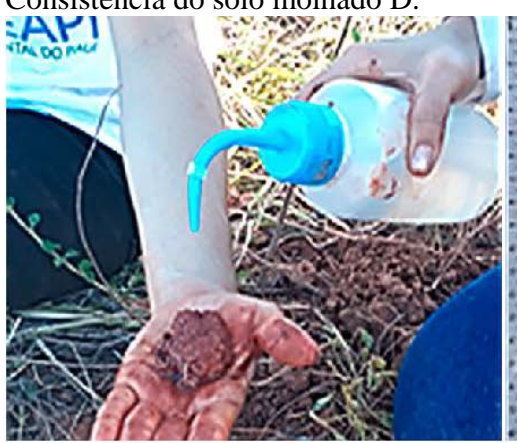

Textura B.

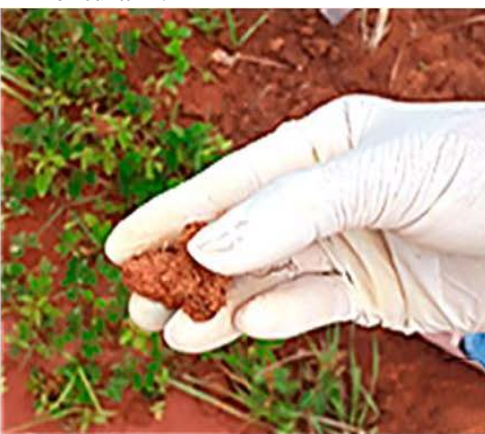

Estrutura E.

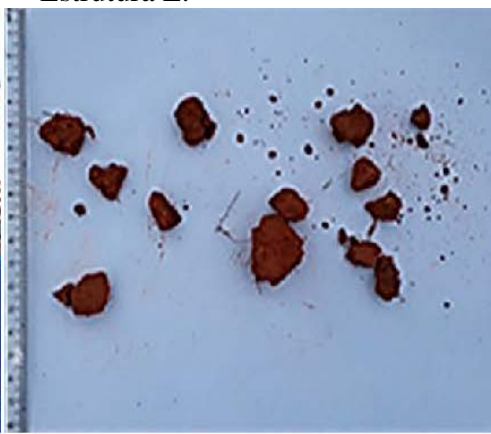

Consistência do solo seco C.

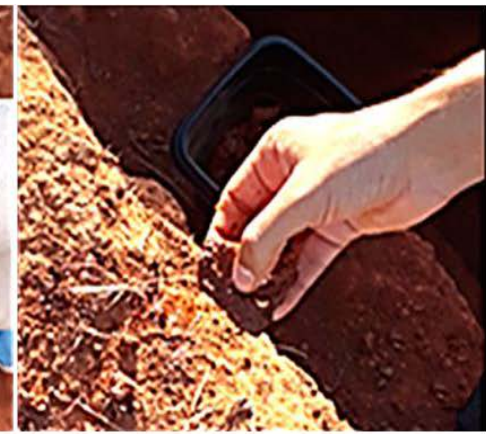

Mosqueado F.

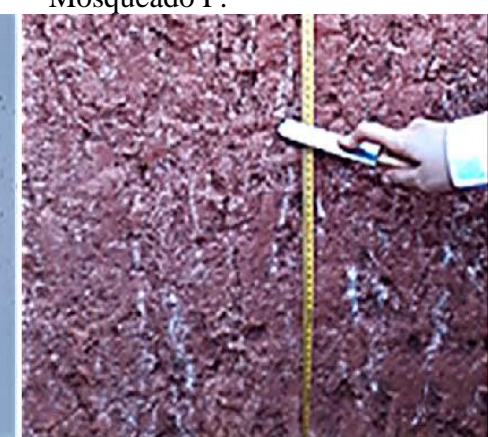

Figura 2. Métodos de avaliação das variáveis morfológicas do solo (A. Coloração do solo; B. Textura; C. Consistência do solo seco; D. Consistência do solo molhado; E. Estrutura; F. Mosqueado).
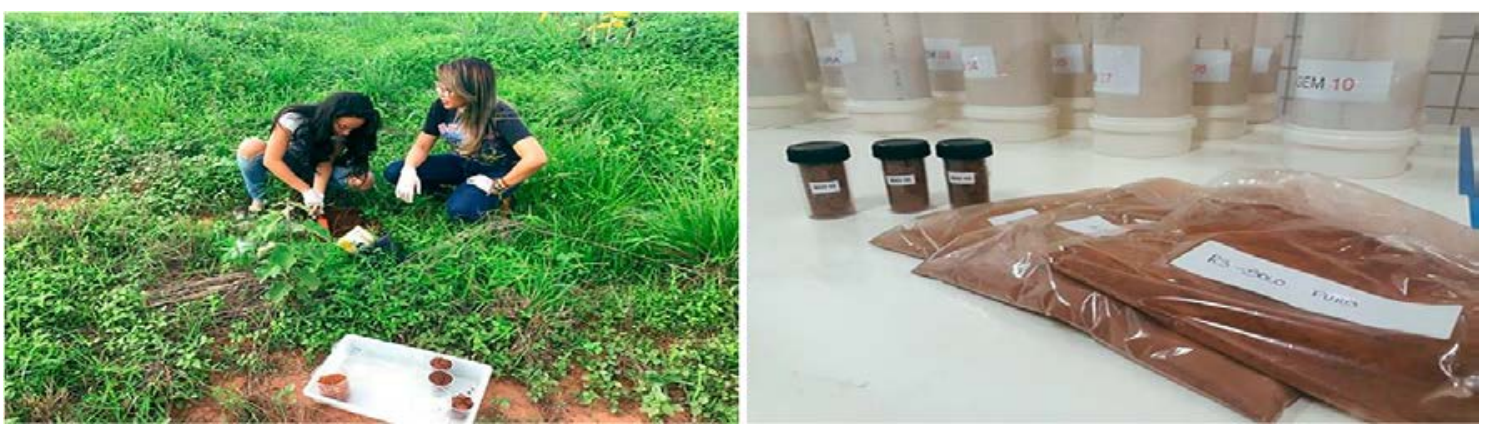

Figura 3. Coleta e armazenamento das amostras de (A e B - Coleta de solo; C- Armazenamento para análise). 


\section{Resultados e discussão}

\section{Caracterização do ambiente (relação solo-paisagem)}

Em relação às análises físicas e químicas como o estudo da geologia do local, o solo estudado foi classificado como um Latossolo Vermelho Amarelo Distrófico Típico, contrapondo com a classificação mais ampla do mapa (Figura
1), realizada pela Solos do Nordeste Embrapa.

Os Latossolos Vermelho Amarelo são profundos e possuem característica química bastante pobre. Segundo Santos (2013), solos são caracterizados principalmente por possuírem saturação por bases baixas nos primeiros $100 \mathrm{~cm}$ do horizonte $B$ e/ou na transição entre o horizonte $\mathrm{AB}$ (Tabela 2).

Tabela 2. Descrição geral do solo estudado.

\begin{tabular}{|l|l|}
\hline DESCRIÇÃO GERAL & \\
\hline Data & $23 / 01 / 2018$ \\
\hline Classificação Anterior & Podzólico Vermelho Amarelo \\
\hline Classificação Sibcs & Latossolo Vermelho Amarelo \\
\hline Unidade de Mapeamento & Law \\
\hline Localização & $\begin{array}{l}\text { Localiza-se no Instituto Federal do Piauí - } \\
\text { Campus Corrente }\end{array}$ \\
\hline Situação, Declive e Cobertura Vegetal & $\begin{array}{l}\text { Amostras coletadas em uma área plana, sob } \\
\text { vegetação do bioma cerrado (alterado) }\end{array}$ \\
\hline Sobre o Perfil & Área construída/Construída \\
\hline Litologia & Cobertura argilo-laterítica \\
\hline Cronologia & Terceário \\
\hline Material de Origem & Sedimentar \\
\hline Pedregosidade & Não pedregoso \\
\hline Rochosidade & Não rochoso \\
\hline Relevo Local & Plano \\
\hline Relevo Regional & Suave ondulado \\
\hline Erosão & Laminar \\
\hline Drenagem & Mal drenado \\
\hline Vegetação Primária & Cerrado (alterado) \\
\hline Uso Atual & Área construída/alterada \\
\hline
\end{tabular}

\section{Descrição morfológica}

Horizonte A

Possui profundidade de $0-20 \mathrm{~cm}$ e uma espessura de $20 \mathrm{~cm}$. Sua coloração é 5/6-7,5 YR (solo seco) e 3/4-5 YR (solo molhado). Dispõe de uma textura argilosa e poros médios. Em relação à consistência: muito duro (solo seco), muito firme (solo úmido), plástico e pegajoso (solo molhado). Detém uma presença fraca de minerais magnéticos, com horizonte moderadamente coeso e raízes muito finas com uma frequência de aproximadamente $30 \%$.
Transição $\mathrm{AB}$

É uma faixa de transição entre os horizontes A e B, na profundidade de 20 $\mathrm{cm}-0,35 \mathrm{~cm}$, e possui uma espessura de $0,15 \mathrm{~cm}$.

\section{Horizonte B}

Encontra-se a partir da profundidade de $0,35 \mathrm{~cm}-1,80 \mathrm{~cm}$ com espessura de $1,60 \mathrm{~cm}$. Sua coloração é 5/8-5 YR (solo seco) e 3/6-2,5 YR (solo molhado). Possui uma textura muito argilosa e poros que variam de muito pequenos a pequenos. Em relação a 
consistências é muito dura (solo seco), muito firme (solo úmido), plástico e pegajoso (solo molhado). É um solo com moderada coesão e a presença de raízes somente nos primeiros $80 \mathrm{~cm}$, onde as mesmas são finas e possui uma frequência de $15 \%$.

\section{Perfil:}

O comportamento de horizontes quanto grau de transição é difuso e a sua forma de transição é plana. Apresenta uma quantidade de mosqueado abundante com manchas grandes e contraste de cores das manchas em relação ao fundo é proeminente (Figura 4).

\section{Descrição das comunidades bacterianas indígenas}

A avaliação de grupos bacterianos presentes indicou uma maior presença de indivíduos com ótima capacidade de adaptação as alterações do meio, isto baseado na contagem de colônias em placas de Petri, no qual verifica uma significativa variação das condições utilizadas, basicamente o meio de cultura, a diluição do inóculo, a temperatura e o tempo de incubação.

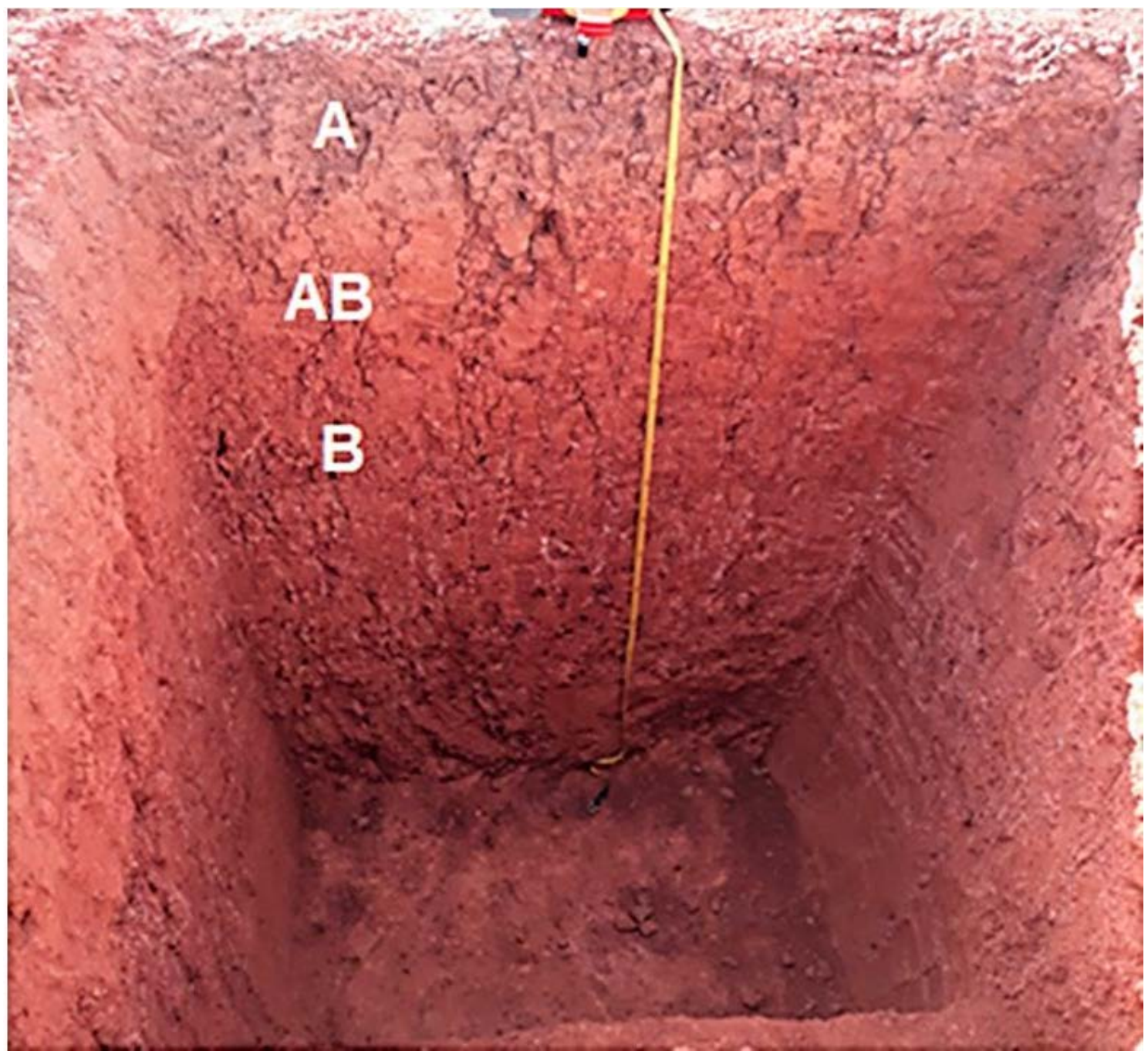

Figura 4. Perfil de solo estudado. 
Desta forma observou-se comportamento variado em relação ao tempo de contagem, principalmente em temperaturas maiores. Analisando o efeito do meio de cultura, verifica - se que os resultados das contagens diárias de bactérias totais variaram de 10 a $251,19 \times 10^{7} \mathrm{UFC} \mathrm{g}^{-1}$ solo seco no meio de TFSA (Terra fina seca ao ar) e de 3,16 a $199,53 \times 10^{7}$ (Tabela 3).

Tabela 3. Número de bactérias totais pelos diferentes dias de contagem, no meio de cultura agar.

\begin{tabular}{lcccccccc}
\hline \multirow{2}{*}{ Diluição } & \multirow{2}{*}{ Temp. } & \multicolumn{7}{c}{ Tempo de Contagem (dias) } \\
\cline { 3 - 9 } & & $\mathbf{1}$ & $\mathbf{2}$ & $\mathbf{3}$ & $\mathbf{4}$ & $\mathbf{5}$ & $\mathbf{6}$ & $\mathbf{7}$ a 10 \\
\hline \multirow{3}{*}{$10^{-5}$} & $30^{\circ} \mathrm{C}$ & 15,80 & 31,60 & 39,80 & 39,80 & 39,82 & 39,82 & 39,82 \\
$10^{-6}$ & $30^{\circ} \mathrm{C}$ & 100,00 & 199,00 & 251,00 & 251,00 & 251,18 & 251,19 & 251,19 \\
$10^{-5}$ & $25{ }^{\circ} \mathrm{C}$ & 10,00 & 25,00 & 31,60 & 39,80 & 39,81 & 39,81 & 39,81 \\
$10^{-6}$ & $25^{\circ} \mathrm{C}$ & 63,10 & 125,80 & 158,50 & 199,50 & 199,50 & 199,50 & 199,50 \\
\hline
\end{tabular}

A temperatura de incubação de $30{ }^{\circ} \mathrm{C}$ permitiu crescimento 1,3 a 1,6 vezes maiores das bactérias totais quando se comparando com a temperatura de $25{ }^{\circ} \mathrm{C}$, em todas as condições. Como era de se esperar, maior número de bactérias foi constatado nos inóculos mais diluídos das amostras de solo, contudo, não se constatou proporcionalidade nas contagens.
Em nível de isolamento foi percebido indivíduos com pelo menos seis comportamentos em placa, podendo qualificar esse grupos distintamente em relação ao meio (Figura 5). Quanto à caracterização dessas colônias foi observado principalmente uma pigmentação alaranjada das mesmas.
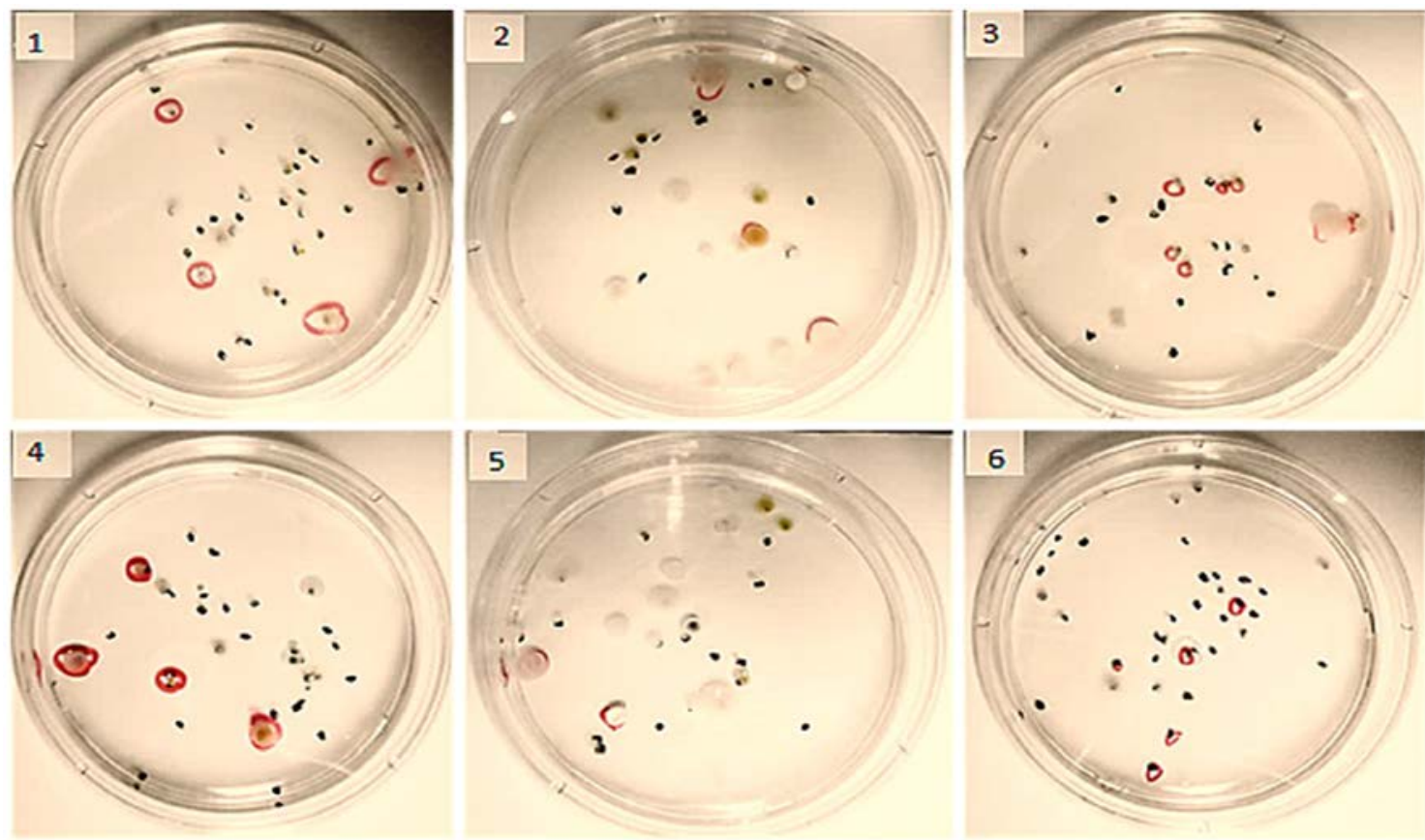

Figura 5. Isolamento de bactérias em meio de cultura.

Rev. Bras. Gest. Amb. Sustent., 2019, vol. 6, n. 12, p. 137-146. 
Em relação ao crescimento foi observado principalmente o crescimento de forma puntiforme, circular e irregular (Figura 6), com margens de destaque as regulares e arredondadas. Em relação à superfície foi verificada a presença de indivíduos com elevação convexa e centro elevado. 0 comportamento principal quanto à densidade é do tipo translúcido, assim como uma superfície embasado e cremoso.

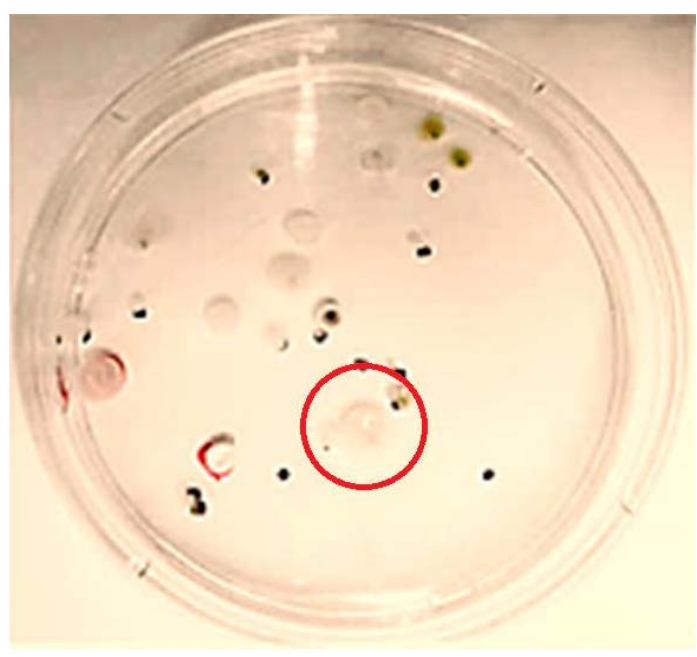

Figura 6. Comportamento translucido das colônias quanto a densidade.

\section{Conclusões}

O solo estudado é classificado como um Latossolo Vermelho Amarelo Distróficos Típicos, o que contrapõe a classificação realizada pela Solos do Nordeste - Embrapa, ao que se verifica um ajuste de escala desse levantamento inicial.

Pode ser considerado um solo profundo, devido o perfil estudado não apresentar fragmentos da rocha matriz em 1, $80 \mathrm{~cm}$. Apresenta horizontes A, B e uma transição $\mathrm{AB}$, podendo ser considerados um solo maduro.
Em relação às comunidades indígenas bacterianas, apresentam uma grande quantidade de bactérias com uma ótima capacidade de adaptação as alterações do meio.

\section{Conflitos de interesse}

Os autores declaram não haver conflitos de interesse.

\section{Referências}

Carrer Filho, R. Actinomicetos como agentes de biocontrole de doenças e como promotores de crescimento do tomateiro. Viçosa: Universidade Federal de Viçosa, 2002. (Dissertação de mestrado)

CEPRO - Fundação Centro de Pesquisas Econômicas e Sociais do Piauí. Diagnóstico Socioeconômico do Município de Corrente. Disponível em: <http://www. cepro.pi.gov.br/download/201309/CEPRO2 7_e46e24deb5.pdf>. Acesso em: 15 jun. 2018.

Hungria, M; Araújo, R. S. Microrganismos de importância agrícola. Brasília: Embrapa SPI, 1994

IBGE - Instituto Brasileiro de Geografia e Estatística. Disponível em: <https://cidades.ibge.gov.br/brasil/pi/corre nte/panorama>. Acesso em: 15 jun. 2018.

Lepsch, I. F. 19 lições de Pedologia. São Paulo: Oficina de Textos, 2011.

Mesquita, V.A. Caracterização da diversidade microbiológica de solo do cerrado em Minas Gerais por eletroforese em gel de gradiente desnaturante (DGGE). Lavras: Universidade Federal de Lavras, 2011. (Dissertação de mestrado).

Moreira, F. M. S; Siqueira, J. O. Microbiologia e Bioquímica do solo. Lavras: UFLA, 2006.

Santos, H. G. Sistema Brasileiro de Classificação de Solos. Brasília: Embrapa, 2013.

Santos, R. D. Manual de descrição e coleta de solo no campo. Viçosa: Sociedade Brasileira de Ciência de solo, 2015. 